\title{
REDRESS COMPLIANCE AND CHOICE: ENHANCED CONSUMER MEASURES AND THE RETREAT FROM PUNISHMENT IN THE CONSUMER RIGHTS ACT 2015
}

\author{
PETER CARTWRIGHT*
}

\begin{abstract}
This article examines critically the extent to which the availability of Enhanced Consumer Measures (ECMs) created by the Consumer Rights Act 2015 addresses the problems associated with the enforcement of consumer protection law in the UK. The article explains the genesis of the provisions by establishing the limitations of the previous law before moving on to consider the extent to which ECMs are successful in addressing those limitations. The article argues that while the availability of ECMs will potentially improve the ability of both enforcers and courts to achieve some objectives of consumer protection law, the measures raise some significant concerns. Of particular concern is the extent to which they signal a move away from prosecution in cases where that would be the optimal response, and so compromise the ability of consumer protection law to achieve some of its most important objectives.
\end{abstract}

KEYWORDS: consumer protection, criminal law, enforcement, consumer rights.

\section{INTRODUCTION}

Consumer law in the UK has always comprised both public and private law. ${ }^{1}$ The principal aims of consumer law include protecting consumers from harm, raising trading standards, and providing redress where harm or loss is caused. The methods by which these relatively simple objectives are achieved are, however, varied and fragmented. Despite considerable attention being paid to the limitations of the criminal law, the objectives of protecting consumers from harm and raising trading standards have longbeen achieved primarily through the creation and enforcement of regulatory offences. ${ }^{2}$

\footnotetext{
*Professor of Consumer Protection Law, University of Nottingham, UK. I would like to thank Richard Hyde of the University of Nottingham, Geraint Howells of the City University of Hong Kong and Claire Andrews of Gough Square Chambers as well as the anonymous reviewer(s) for helpful comments on earlier drafts. The usual disclaimer applies. Address for Correspondence: School of Law University of Nottingham NG7 2RD, UK. Email: peter.cartwright@nottingham.ac.uk.

${ }^{1}$ The number of laws is too great to repeat here.

${ }^{2}$ P. Cartwright, Consumer Protection and the Criminal Law (Cambridge 2001).
} 
The enforcement of these offences may be formal (through prosecution) or informal (through compliance strategies). ${ }^{3}$ However they are enforced, regulatory offences in areas such as consumer protection and environmental law have been found to be of limited utility in achieving the objectives they might be expected to achieve. ${ }^{4}$ Where the civil law provides enforcers with mechanisms for preventing harm (such as through the seeking of undertakings and the making of orders under part 8 of the Enterprise Act) it has also been found wanting. This is both because of the cumbersome procedures that enforcers must follow, and because of the limited remedies they could obtain. With regard to redress, emphasis has long been placed upon what has been called the "individual claims paradigm" with affected individuals expected to pursue their rights. ${ }^{5}$ Whether it be enforced through the courts or through alternative dispute resolution (ADR) the private law has remained central. This is a significant constraint on the achieving of justice for consumers as the transaction costs they face in seeking redress will frequently be prohibitive. ${ }^{6}$ As Leff famously commented: "[o]ne cannot think of a more expensive and frustrating course than to seek to regulate goods or 'contract' quality through repeated lawsuits against inventive 'wrongdoers. ${ }^{\prime \prime \prime}$

The Consumer Rights Act 2015, which received Royal Assent on $26^{\text {th }}$ March, makes highly significant changes to these areas of consumer law in the UK. Much attention has been paid to its implications for consumer contract law, especially in reforming the private law relating to sale of goods, supply of services and digital content, and unfair contract terms. However, the Act also makes highly significant changes to the regulatory side of consumer law (what is perhaps more commonly called consumer protection law) through the creation of Enhanced Consumer Measures (hereafter, ECMs). These changes have major implications for the success of consumer law as a form of protection, as a way of raising standards, and as a means to facilitating redress. They therefore go some way towards securing some of the principal objectives of consumer protection law. They also potentially assist consumers to play the role envisaged for them by classical economic theory of making informed choices in accordance with their preferences and so exercising market discipline. ${ }^{8}$

This article examines critically the extent to which the availability of ECMS addresses the problems associated with the enforcement of consumer protection law in

\footnotetext{
${ }^{3}$ See R. Macrory, Regulatory Justice: Making Sanctions Effective (Nov 2006) and A.J. Reiss, "Selecting Strategies of Social Control Over Organisational Life" in K. Hawkins and J. Thomas (eds), Enforcing Regulation (Boston 1984)

${ }^{4}$ R. Macrory Regulatory Justice.

${ }^{5}$ See T. Wilhelmsson "Consumer Law and Social Justice" in I. Ramsay (ed) Consumer Law in the Global Economy (Aldershot 1997) 217.

${ }^{6}$ Ibid.

${ }^{7}$ A Leff "Unconscionability and the Crowd: Consumers and the Common Law Tradition" (1970) University of Pittsburgh L Rev 349 at 356.

${ }^{8}$ I. Ramsay Rationales for Intervention in the Consumer Marketplace (London 1984).
} 
the UK. The article begins by explaining the genesis of the provisions by establishing and explaining the principal limitations of the previous law. It then moves on to consider in detail the extent to which ECMs are successful in addressing those limitations. The article argues that while the availability of ECMs will potentially improve the ability of both enforcers and the courts to achieve some of the most important objectives of consumer protection law, they nevertheless raise some significant questions. Of particular concern is the extent to which they signal an undesirable move away from prosecution in cases where that would be the optimal response and so compromise the ability of consumer protection law to achieve some of its most important objectives. ${ }^{9}$

\section{THE NEED FOR REFORM}

A. Protecting Consumers through the Regulatory Offence: characteristics and shortcomings

It is widely recognised that enforcers have lacked the enforcement tools to allow them to achieve their objectives satisfactorily. The Hampton Report ("Hampton") was established to consider how administrative burdens on business might be reduced by promoting more efficient approaches to regulatory inspection and enforcement while not reducing regulatory outcomes. Hampton made a number of recommendations, including the greater use of risk-assessments and better targeting of resources. ${ }^{10}$ It also recommended the establishment of a review of regulators' penalty regimes, which it viewed as operating ineffectively, particularly as a deterrent. ${ }^{11}$ The review was undertaken by Professor Richard Macrory who produced a consultation document (Regulatory Justice: Sanctioning in a post-Hampton world) which analysed the shortcomings of the existing law and set out a taxonomy of "Penalties Principles" that might be applied in future ${ }^{12}$ This led to the final report Regulatory Justice: Making Sanctions Effective. ${ }^{13}$ The references to Regulatory Justice below are to the consultation paper where the principles were developed.

Regulatory Justice concluded that enforcers relied too heavily upon securing compliance with norms by prosecuting (or threatening to prosecute) traders for breach of regulatory offences. ${ }^{14}$ The principal reason for this was that enforcers lacked tools to help them to achieve their objectives. Other studies have confirmed these shortcomings

\footnotetext{
${ }^{9}$ This contrasts sharply with a theme identified a decade earlier towards criminal sanctions in regulation. See in particular R. Baldwin "the New Punitive Regulation" (2004) 67(3) M.L.R. 351.

${ }^{10}$ P. Hampton Reducing Administrative Burdens (London March 2005)

${ }^{11}$ Ibid recommendation 8 .

${ }^{12}$ Regulatory Justice: Sanctioning in a post-Hampton World (May 2006) (hereafter "Macrory") CHECK

${ }^{13}$ Regulatory Justice: Making Sanctions Effective (November 2006).

${ }^{14}$ Macrory chap 2.
} 
in the context of consumer protection law, with particular focus on the difficulties consumers faced in receiving redress (broadly understood). ${ }^{15}$

While not formally distinct from more mainstream criminal law, regulatory offences are said to possess certain characteristics. According to Ramsay, those characteristics are as follows. ${ }^{16}$ First, regulatory offences impose strict liability, tempered by statutory defences. Second, they employ fines as the primary sanction. Third, they are enforced by a specialised bureaucracy who will exercise discretion in the form of compliance strategies. Finally, cases are heard mainly in the magistrates courts with higher courts playing a role in the interpretation of the statute in question. To this, we might add two elements: that such offences typically require the defendant to be acting in the course of business, and that they may lack the stigma more commonly associated with the label of criminality. ${ }^{17}$ Regulatory Justice identified the following as particular limitations of regulatory offences.

First, regulatory offences are inadequate as a deterrent. ${ }^{18}$ Traders know that they will seldom be prosecuted, and that when they are, penalties are likely to be low. The theory of optimal deterrence suggests that a rational firm will comply where $p D>U$, where $p$ represents the perceived probability of apprehension and conviction, $D$ the perceived cost of contravention and $U$ the perceived benefit from contravention. ${ }^{19}$ While this model may not reflect accurately the motivation of many firms, to the extent that firms are purely profit maximisers or "amoral calculators" it seems unlikely that regulatory offences operate effectively as deterrents. One reason is that regulatory offences are typically enforced through "compliance strategies". A compliance strategy has been said to have as its aim securing conformity with the law "by means of ensuring compliance or by taking action to prevent potential law violation without the necessity to detect, process and penalise violations." 20 This contrasts with a deterrence strategy, the aim of which is "to secure conformity with the law by detecting violation, determining who is responsible for the violation, and penalising violations to deter violations in the future, either by those who are punished or by those who might do so were violations not penalised". ${ }^{21}$ The use of compliance strategies can be justified on a number of grounds. In particular, informal action such as persuasion or negotiation may use far fewer resources than formal action; but such an approach is also likely to create better

\footnotetext{
${ }^{15}$ J. Peysner and A. Nurse Representative Actions and Restorative Justice (Lincoln Dec 2008); UEA Benchmarking the UK Framework Supporting Consumer Empowerment (ESRC Centre for Competition Policy 2008).

${ }^{16}$ I. Ramsay Consumer Law and Policy 3rd ed (Oxford 2012), 221-22.

17 See P. Cartwright "Crime Punishment and Consumer Protection" (2007) 30 J.C.P. 1

${ }^{18}$ Macrory para 2.6.

${ }^{19}$ See G. Becker "Crime and Punishment: An Economic Approach" (1968) 76 Jl. Pol. Econ 169 and A. Ogus Regulation : Legal Form and Economic Theory (Oxford 1994), 91

${ }^{20}$ Reiss "Selecting Strategies" 23

${ }^{21}$ Ibid 22-23.
} 
relations between enforcer and trader. Many contraventions of consumer protection law are accidental rather than intentional, and formal action may be a disproportionate and counterproductive response; this is particularly so where the harm is small and the trader is eager to comply. The predominance of compliance strategies does not mean that enforcers will never prosecute, nor that they will fail to negotiate with the threat of such action in the background. Ayres and Braithwaite conclude that the optimal enforcement approach is what they describe as "tit for tat". ${ }^{22}$ This means that the enforcer only shifts from a co-operative to a deterrent approach "when the firm yields to the temptation to exploit the co-operative posture of the regulator and cheats on compliance". ${ }^{23}$ This may reflect the approach of enforcers where consumer protection is concerned.

Second, the Report suggests that prosecution is sometimes a disproportionate response to a contravention. ${ }^{24}$ While this may appear paradoxical to the first point above, it demonstrates the unpredictability of both prosecution and the effect of conviction. Well-informed traders are likely to know the maximum penalty that a court can impose for breach of a particular provision, and may even know the penalty that a court is likely to impose for such breach. However, the trader will not be able to predict the other impact that results from conviction, in particular from adverse publicity. ${ }^{25}$ While the fear of such publicity might improve the operation of regulatory offences as deterrents, its consequences could be disproportionate to the harm and wrongdoing involved. ${ }^{26}$

A third criticism is that regulatory offences are resource-intensive. ${ }^{27}$ Ogus found that in relation to consumer protection offences, trading standards officers would typically spend one day investigating a contravention, two issuing informal cautions, four issuing formal cautions and ten preparing prosecutions. ${ }^{28}$ Data presented to BIS by Surrey Trading Standards suggested that the average cost of bringing a criminal case was $£ 1270$ where guilty plea was entered and $£ 3860$ where the case was contested. ${ }^{29}$ It is difficult to assess precisely the impact this has on enforcement behaviour. However, it is reasonable to assume that enforcers will be reluctant to prosecute unless they are confident of success and do not have an appropriate alternative route.

\footnotetext{
22 I. Ayres and J. Braithwaite Responsive Regulation: Transcending the Deregulation Debate (New York 1992) ${ }^{23}$ Ibid 21.

${ }^{24}$ Macrory para 2.24.

${ }^{25}$ See J.C. Coffee Jr "No Soul to damn no Body to kick" An Unscandalized Inquiry into the Problem of Corporate Punishment" (1981) 79 Mich. L. Rev. 386

${ }^{26}$ This relates to the issue of stigma, considered below.

${ }^{27}$ Macrory para 1.14 .

${ }^{28}$ A. Ogus "Better Regulation-Better Enforcement" in S Weatherill (ed) Better Regulation (Oxford 2007), 107, 112.

${ }^{29}$ BIS Civil Enforcement Remedies - Extending the range of remedies available to public enforcers of consumer law - impact assessment (Impact Assessment) November 2012 para 25.
} 
Fourth, Regulatory Justice suggested that regulatory offences can lead to compliance deficit. ${ }^{30}$ One reason enforcers seem to find it difficult to secure compliance is that they are limited in the extent to which they can require firms to act in specific ways to bring themselves back into compliance and to ensure that breaches are less likely to happen in future. This is addressed in detail later.

Fifth, concern was expressed that conviction does not necessarily reflect the stigma that should be attached to the wrongdoing in question. ${ }^{31}$ There are two concerns here: first that prosecution generates excessive stigma, and second that it generates insufficient stigma. One aim of punishment under the criminal law is to ensure just deserts, and inappropriate labelling can compromise this. Any conviction should, so far as possible, reflect the seriousness of the wrongdoing, and the principal elements of such seriousness are culpability and harm. Most regulatory offences are over-inclusive in that they are satisfied where there is little or no harm and/or culpability. ${ }^{32}$ However, some breaches of regulatory offences involve significant levels of harm and culpability. The regulatory offence is a rather blunt and inflexible tool which is ill-suited to respond to demands of a regime seeking to ensure just deserts, and the fact of conviction risks leaving an inappropriate label attached to the defendant.

Finally, Regulatory Justice contended that prosecuting a trader for a regulatory offence does not focus sufficiently on victims. ${ }^{33}$ This is surely correct. In the context of consumer protection, prosecution has been widely regarded as an ineffective means of achieving restoration/redress. ${ }^{34}$ Victims will frequently not be involved in proceedings and in many cases will not be traced. However, as will be explained below, it is important to remember that there are now several routes to redress that were unavailable at the time Regulatory Justice was published, and so the criticism may not be as compelling as it was previously. ${ }^{35}$

The shortcomings of regulatory offences, and in particular of prosecution as the means of enforcing them, loomed large in the decision to create ECMs. But equally important were the limitations of the other principal enforcement tool available to consumer protection enforcers, namely the ability to seek enforcement orders under Part 8 of the Enterprise Act 2002.

B. Civil Enforcement and Part 8 of the Enterprise Act 2002: Role and Shortcomings

\footnotetext{
${ }^{30}$ Macrory para 2.27.

${ }^{31}$ Macrory paras 2.24 and 3.25.

${ }^{32}$ Neither mens rea nor damage/loss are typically required for guilt.

${ }^{33}$ Macrory para 1.21 .

${ }^{34}$ See e.g Peysner and Nurse Representative Actions.

${ }^{35}$ See below.
} 
Part 8 of the Enterprise Act gives enforcers powers to obtain undertakings from traders and to apply to the courts to make enforcement orders against such traders, where they breach their legal obligations in a way that harms the collective interests of consumers. Breaches are classified as either "domestic infringements" or "Community infringements". ${ }^{36}$ A "Community Infringement" is an act or omission which harms the collective interests of consumers and which contravenes particular legislation (including the Unfair Commercial Practices Directive 2005 which was implemented in the UK by the Consumer Protection from Unfair Trading Regulations 2008). Domestic infringements include breaches of many consumer laws, broadly understood, including those found in the Consumer Rights Act 2015.

The shortcomings of Part 8 have been well-documented, and it will be seen that some of these (particularly with regard to procedure) remain under the new regime. According to s.214(1) of the Enterprise Act, before making an application for an enforcement order an enforcer must engage in "appropriate consultation" with the person against whom the order would be made. The period of consultation is at least 14 days beginning with the day on which notice is given. However, this is reduced to seven for an interim order. ${ }^{37}$ An interim order can be made where "it is expedient that the conduct is prohibited or prevented (as the case may be) immediately". ${ }^{38}$ What amounts to appropriate consultation in practice is not entirely clear. ${ }^{39}$ Lewin and Kirk argue that the compliance strategies typically adopted by enforcers and discussed above (what they call "traditional engagement with traders") will satisfy the requirement, as would interviews, particularly if it is made clear that part 8 action is envisaged. ${ }^{40}$ Consultation can be seen as an important element of the process in that it gives the enforcer the opportunity to be better-informed about the circumstances of the case of the trader. It is different from giving notice, and may be particularly important where a well-intentioned trader is receptive to taking steps to prevent contraventions in future.

Under s.219, if an enforcer has the power to apply for an enforcement order he may instead accept an undertaking from the person. An undertaking will be complied with if the person does not continue or repeat the conduct, engage in such conduct in the course of his business or another business, and does not consent to or connive in the carrying out of such conduct by a body corporate with which he has a special relationship. ${ }^{41}$ In considering whether to make an enforcement order, the court will have regard to whether the person has given an undertaking and has failed to comply with the

\footnotetext{
${ }^{36}$ Sections 211 and 212 respectively.

${ }^{37}$ Section 214 (1A).

${ }^{38}$ Section $218(1)(\mathrm{c})$.

${ }^{39}$ Section 214(2) defines it as consultation for the purpose of achieving particular objectives such as cessation of, or ensuring there is no repetition of, an infringement.

${ }^{40}$ B. Lewin and J. Kirk Trading Standards Law and Practice $2^{\text {nd }}$ ed (Bristol 2011) 49.

${ }^{41}$ Section 219(4).
} 
undertaking. The court may, as an alternative to making an order, accept an undertaking from the person. Breaching an undertaken given to, or an order made by, the court places the person in contempt of court.

The limitations of part 8 were in part demonstrated by how rarely it was used. In 2011-12 just seven enforcement orders were made and 99 undertakings given, and these figures were not atypical. ${ }^{42}$ There are two main explanations for the reluctance of enforcers to use part 8 . The first is that the procedure described above is so cumbersome that it provides a significant disincentive to using the provision. Recently, research undertaken by Karen Clubb on the mis-selling of mobility aids found widespread dissatisfaction among trading standards officers about the utility of part $8 .{ }^{43}$ Conversations the author has had with enforcers have confirmed these conclusions more generally. However, this is not the view of all commentators. Lewin and Kirk describe part 8 as "a flexible, fast and elegant way of dealing with consumer detriment" where used properly. ${ }^{44}$ This appears to be a minority view. In the relatively rare event of a case going to court there will be significant costs attached. The London Borough of Brent, for example, has estimated that the typical cost of a civil case was approximately $£ 3375 .{ }^{45}$ This will provide a disincentive for enforcers to use the procedure and the known reluctance to go to court may encourage less reputable traders to drag out the process. As Baroness Crawley observed at the second reading of the Consumer Rights Bill in the House of Lords: "use of these measures has, in the past, been modest at best, through a combination of complexity of process, cost and risk to enforcers." 46

An equally compelling explanation for the reluctance to use part 8 concerns the limitation in what it could achieve. Before the Consumer Rights Act 2015, part 8 did not impose any new obligations on businesses; it merely helped to ensure compliance with existing obligations. Traders could only be obliged to (a) stop breaking the law; and (b) agree not to break it in future. Perhaps the most striking weakness of part 8 in this regard was that it did not incorporate a mechanism through which consumers could receive compensation or similar redress. Although enforcement orders are admissible as evidence in civil proceedings, consumers still needed to seek redress through the courts or through an alternative means of dispute resolution. ${ }^{47}$ In addition, part 8 did not allow enforcers or the courts to require businesses to take specific steps to improve the

\footnotetext{
${ }^{42}$ BIS Impact Assessment para 23.

${ }^{43}$ See

http://www.derbyshire.gov.uk/images/University\%20of\%20Derby\%20Research\%20Project\%20into\%20the\%20 Mis-selling\%20of\%20Mobility\%20Aids\%20121113_tcm44-234260.pdf

${ }^{44}$ In their view, difficulties have arisen primarily through choosing inappropriate cases and creating undue delays. Lewin and Kirk Trading Standards Law 45.

${ }^{45}$ BIS Impact Assessment para 26. Trading standards officers now have rights of audience although it is not clear how frequently they will present the case.

${ }^{46}$ Consumer Rights Bill 1 July 20141666.

${ }^{47}$ Although enforcement orders are admissible as evidence in civil proceedings.
} 
probability of compliance in future. Just as prosecution can be viewed as a blunt instrument to achieve the main objectives of consumer protection policy, so could part 8 . To the extent that these limitations explain the reluctance to use Part 8 , the proposed reforms may make it a more attractive prospect. It is to the reforms that we now turn.

\section{III: REFORM THROUGH ENHANCED CONSUMER MEASURES}

\section{A. Objectives and Choices}

Difficulties with ensuring the effective enforcement of consumer law through the combination of prosecution and part 8 led the Government to look at reform. In its paper Civil Enforcement Remedies, the Department for Business Innovation and Skills (BIS) identified the key outcomes it sought as follows. ${ }^{48}$ First was improving business compliance with the law; it aimed to achieve this by developing what it described as "forward looking measures to ensure the same or similar breach does not reoccur". ${ }^{49}$ Second was improved redress for consumers affected by the breach of consumer law. This would be ensured by providing appropriate consumer redress schemes. The third objective was to develop more confident consumers who are empowered to exercise greater consumer choice. BIS saw this as being achieved by "measures to improve the ability of new and existing customers to make a free and informed choice". ${ }^{50}$

To some extent, these objectives reflected the "Penalties Principles" outlined in Regulatory Justice. ${ }^{51}$ Macrory hoped these would build "a common understanding of what a sanctioning regime should achieve amongst regulators and the regulated community, and in turn... act as a framework for regulators when considering what sort of sanction or enforcement action to take." ${ }^{52}$ According to the Principles, a sanction should do the following: aim to change the behaviour of the offender; aim to eliminate any financial gain or benefit from non-compliance; be responsive and consider what is appropriate for the particular offender and regulatory issue, which can include punishment and the public stigma that should be associated with a criminal conviction; be proportionate to the nature of the offence and the harm caused; aim to restore the harm caused by regulatory non-compliance, where appropriate; and aim to deter future noncompliance. ${ }^{53}$ These will be reflected upon in the context of the reforms.

The Government identified two ways of meeting its objectives. The first was giving enforcers additional administrative powers along the lines of those contained in

\footnotetext{
${ }^{48}$ BIS Civil Enforcement Remedies: Consultation on extending the range of remedies available to public enforcers of consumer law ("Civil Enforcement Remedies") (Nov 2012) para 4.

49 Ibid

${ }^{50}$ Ibid

51 Macrory.

${ }^{52}$ Macrory Making Sanctions Effective para 2.3.

${ }^{53}$ Macrory box E2.
} 
the Regulatory Enforcement and Sanctions Act 2008 (RESA) and the second was giving the courts additional powers in the making of orders under the Enterprise Act. ${ }^{54}$ There were strong arguments for some form of civil penalties regime. Macrory interpreted the notion of "sanctions" and "penalties" very broadly to include tools that involve some element of punishment and those which are focused instead on achieving an outcome regardless of any punitive notion. However, the Government decided instead to extend the range of remedies covered by Enforcement Orders. These provisions, known now as Enhanced Consumer Measures (ECMs) are contained in Schedule Seven of the Consumer Rights Act 2015 (CRA).

ECMs are central to the reforms the CRA makes to part 8 of the Enterprise Act and operate in two ways. First, when the court makes an enforcement order or accepts an undertaking from a trader, it will now be able to attach to them a range of ECMs. Instead of merely requiring the trader to stop breaching the law, the court will be able to require the trader to take a series of positive actions. Second, where an enforcer has agreed undertakings under Part 8, those undertakings may include ECMs. Again, the trader can therefore be required to act in a particular way, rather than merely required not to act in a particular way. The powers are open to all enforcers under Part 8 including Which?, the only designated private enforcer. As they are based on the powers in part 8 , they can be used to tackle breaches and potential breaches of a variety of consumer protection law. However, this article focuses particularly on their use where criminal laws are breached.

There are three categories of ECM: the redress category; the compliance category; and the choice category, and the measures may be used either individually or in combination. ${ }^{55}$ There will be occasions, for example, where it is appropriate for a trader to be required to pay redress, change its conduct, and publicise the details of its infringements. This is particularly important, because, as will become apparent, the different types of measure have specific objectives and address different weaknesses in the enforcement regime. However, there are a number of constraints placed upon enforcers which may reduce the ability to do this in practice. For example, section 291B(1) states that an enforcement order or undertaking may include only such enhanced consumer measures as the court or enforcer considers to be just and reasonable. Particular attention must be paid to the proportionality of the measure, taking into account:

(a) The likely benefit of the measures to consumers;

\footnotetext{
${ }^{54}$ BIS Civil Enforcement Remedies: chap 2. RESA was introduced as a way of implementing Macrory's proposals but does not apply to consumer protection.

${ }_{55}$ BIS Enhanced Consumer Measures - Guidance for Enforcers of Consumer Law May 2015 ("2015 Guidance") Case Study 3.
} 
(b) The costs likely to be incurred by the subject of the order or undertaking (namely the cost of the measures and the reasonable administrative costs associated with taking the measures); and

(c) The likely cost to consumers of obtaining the benefit of the measures.

It is customary for proportionality to be demanded of enforcers, either in legislation or through other means (such as the Regulators' Code). This is entirely proper. Indeed, Regulatory Justice emphasised that any sanction (a term that, as noted above, was used extremely broadly) should be proportionate to the nature of the offence and the harm caused. ${ }^{56}$ But if we look further at the limitations placed on some ECMs there may be some concerns with how practical these demands are. This is most obviously the case in relation to redress schemes. Each category is now examined in turn.

\section{B. ECMs: The Redress Category}

Section $219 \mathrm{~A}(2)$ states that measures in the redress category are:

(a) measures offering compensation or other redress to consumers who have suffered loss as a result of the conduct which has given rise to the enforcement order or undertaking,

(b) where the conduct referred to in paragraph (a) relates to a contract, measures offering such consumers the option to terminate (but not vary) that contract,

(c) where such consumers cannot be identified, or cannot be identified without disproportionate cost to the subject of the enforcement order or undertaking, measures intended to be in the collective interests of consumers.

This category provides enforcers with a tool to address some of the limitations of consumer law identified above by providing consumers with redress. That redress might be in the form of financial compensation, or in the right to terminate a contract, presumably with the normal restitutionary consequences. Although not presented as such in the Legislation, redress measures are the primary form of ECM in that where taking action under all three measures would be disproportionate, redress measures take priority. ${ }^{57}$ As noted above, Regulatory Justice identified one of the weaknesses of the regulatory offence as being the lack of focus it placed on the victim. It also emphasised the importance of having provisions which aim to restore the harm that was caused by

\footnotetext{
${ }^{56}$ Macrory box E2.

${ }^{57} 2015$ Guidance para 48.
} 
regulatory non-compliance. In the context of consumer protection restoration, in the form of redress, is especially important. For that reason, particular attention is paid here to the redress category.

\section{The roles of enforcer and trader}

There is uncertainty about the extent to which traders or enforcers act as the genesis for redress. At the time of the consultation, it was central to the Government's vision that the trader should come up with a proposed solution. The Government stated that its aim was that "the business would propose a scheme which they would agree with the relevant enforcer" although "where the business is unwilling to propose an appropriate scheme, the enforcer could seek a requirement through the civil courts that the trader offers redress to consumers. ${ }^{\prime 58}$ This reflects one of the aims of Regulatory Justice- that businesses should be able to offer creative solutions to breaches. ${ }^{59}$ In its written briefing on the Bill, the Law Society argued that this was an important element in the rationale for ECMs but noted that the Bill had not made reference to this. ${ }^{60}$ The Guidance makes it clear that businesses can suggest solutions. It states, for instance, that the Legislation does not list possible measures, partly to enable the enforcer to choose the most appropriate measure but also to enable the business "to have the flexibility to suggest their own measures to put right the detriment they have caused. ${ }^{\prime 61}$ The Guidance does, however, emphasise the primary role of the enforcer, stating that " $[i] n$ the first instance the enforcer should seek to work with the trader that has breached to law to identify suitable measures to deal with the breach." ${ }^{12}$ It later states: "we expect in most cases that the enforcer will propose the measures to be put in place. ${ }^{\prime 63}$

This represents a shift in the balance of responsibilities from the business to the enforcer. In some ways this may be understandable. ECMs are an alternative to other forms of enforcement action, so it may be reasonable for the enforcer to take an objective view of what, precisely, the trader should be required to do. However, placing the onus on enforcers in this way does have shortcomings. First, it might be viewed as an impediment to the objective of responsibilising traders. Regulation is most likely to be successful where it incentivises firms to comply with norms in the first place and to take responsibility for harm where it has been caused. Responsive regulation, as explained by Ayres and Braithwaite, recognises that traders will feel under incentives to do this where

\footnotetext{
${ }^{58}$ BIS Draft Consumer Rights Bill Government Response to the Consultations on Consumer Rights June $2013 \mathrm{p}$ 48.

${ }^{59}$ This takes the form of enforcement undertakings in RESA.

${ }^{60}$ Law Society Civil Enforcement Remedies January 2013.

${ }^{61} 2015$ Guidance para 45.

${ }^{62} 2015$ Guidance para 28.

${ }^{63} 2015$ Guidance para 73.
} 
they see enforcers responding positively to appropriate behaviour. ${ }^{64}$ Generating an expectation that traders will initiate discussions and offer solutions helps to create a culture of responsibility. Indeed, on the assumption that traders are more likely to comply where they feel some ownership of the solution, it may be more effective to encourage and incentivise traders to develop their own responses. Second, it is a widelyaccepted criticism of both prosecution and part 8 that they are resource- intensive. There is ample evidence a recalcitrant trader can cause significant difficulties for an enforcer wishing to use Part 8 , and while this problem remains under the new regime, it might be mitigated by giving traders some influence (at an earlier stage) over the content of ECMs. To the extent that traders rather than enforcers develop proposals for redress, enforcers' (increasingly) scarce resources are protected.

\section{Proportionality, redress and deterrence}

In addition to the requirement for proportionality noted above, section $219 \mathrm{~B}(4)$ states that an order or undertaking may include enhanced consumer measures in the redress category:

(a) only in a loss case, and

(b) only if the court or enforcer (as the case may be) is satisfied that the cost of such measures to the subject of the enforcement order or undertaking is unlikely to be more than the sum of the losses suffered by consumers as a result of the conduct which has given rise to the enforcement order or undertaking.

This means that redress measures can only be used if the amount payable as compensation is likely to be no more than the losses suffered by consumers as a result of the conduct. It is the responsibility of the enforcer to decide whether redress should be paid, to calculate the loss that consumers have suffered and to calculate the cost to the trader of compliance. ${ }^{65}$ The OFT raised significant concerns about this. ${ }^{66}$ First, it doubted whether such obligations were necessary, given that enforcers are required to comply with the better regulation principles and the regulators' code in relation to the use their powers. Second, it drew attention to the consequences of failing to quantify these elements accurately. If the enforcer underestimates the detriment and the amount of redress available, consumers may challenge the scheme or ignore it. If the trader alleges that the enforcer has underestimated the cost of compliance it may challenge the measures as being disproportionate. The OFT concluded that it would be preferable to adopt a model similar to that found in the Financial Services and Markets Act 2000,

\footnotetext{
${ }^{64}$ Ayres and Braithwaite Responsive Regulation.

652015 Guidance para 53.

${ }^{66}$ OFT Consultation Response
} 
where greater onus is placed on the business to carry out investigations, provide the enforcer with information and consult before establishing the scheme. ${ }^{67}$ Of course, where redress schemes are proposed, businesses will play an important role in operating those schemes, for example by identifying and contacting consumers.

Regulatory Justice stated that one aim of a sanction was to eliminate the financial gain or benefit from non-compliance. The Redress measures focus less on ensuring that a trader does not gain from contravention, and more on ensuring that the measures do not impose a greater cost on the trader than the loss to the consumer. In the desire to ensure proportionality, it might be argued that sight has been lost of the need to eliminate any gain and provide appropriate redress. Moreover, by focusing on the need to avoid benefits to consumers being greater than losses to traders, the need for deterrence could be lost.

One justification for placing such stringent obligations on enforcers is that the redress category is concerned solely with redress. It is not to be viewed as a punishment or, as the term is typically used, a sanction. However, it is submitted that ECMs should be able to play a role in deterrence. In this regard, they appear to fall short. A profit-maximising trader which believes it is unlikely to be prosecuted for a consumer protection offence may decide to cause loss to consumers safe in the knowledge that it will not be required through the redress category to pay more than the consumers have lost. Referring back to optimal deterrence, the perceived benefit of contravention outweighs (perhaps significantly) the perceived detriment. Most traders will not be quite so calculating; and there is evidence that traders comply with the law for a range of reasons beyond the threat of a sanction or financial loss. ${ }^{68}$ However, some will take advantage and the restrictions on enforcers' powers appear to limit the ability for redress measures to ensure deterrence. While the principal aim of redress measures is to provide redress, given that they will frequently be used as an alternative to prosecution, it is important that deterrence is not lost.

It is true that there are some ways in which redress measures may still incorporate an element of deterrence. First, the cost referred to in section 219B(4)(b) does not include the administrative costs associated with taking the measures. In practice, that may provide some limited deterrent, as the costs of complying with the measure may mean that a trader will be obliged to expend more through a combination of compensation and compliance costs that $s /$ he received as a result of the contravention. Second, it is possible that the trader will receive some negative publicity as a result of establishing the scheme. The choice category (considered below) is largely premised on the desirability of consumers having information about the wrongdoing (broadly

\footnotetext{
${ }^{67}$ Ibid

${ }^{68}$ See e.g. OFT Consumer Law and Business Practice (OFT 1225 June 2010); S Oded Corporate Compliance (Cheltenham 2013) para 3.2.1.
} 
understood) of traders, but that information may also emerge through the creation of redress schemes. The CRA makes clear that a publication requirement that is included in an enforcement order or undertaking is not an ECM, and businesses are often required to publish the terms of undertakings along with a corrective statement. Publication is important both to inform consumers of the trader's wrongdoing, and to assist monitoring that trader's conduct to see if undertakings or orders are breached. Regulatory Justice saw it is important that enforcers should consider what is appropriate including the stigma that should be associated with a criminal conviction. ${ }^{69}$ It should be remembered that ECMs will generally be used where there is no conviction, and may be used where there is no offence (although this article is of course focusing on where the criminal law has been breached). Negative publicity will generally aid deterrence but it is vital for proportionality and fair labelling, that it accurately reflects the wrongdoing involved.

\section{Redress measures in context}

It is easier for consumers to receive redress under other provisions than it was when ECMs were first being formulated. This is an important factor in assessing the costs and benefits of redress under the CRA. First, section 63 of the Legal Aid, Sentencing and Punishment of Offenders Act 2012 inserts into s.130 of the Powers of Criminal Courts (Sentencing) Act 2000 an obligation for the court to consider making a compensation order in any case where the section empowers it to do so. Where a prosecution is successful, for example under the CPUTRs, and a consumer has suffered loss, the use of this power avoids consumers having to pursue the matter further. While this will be useful in some cases, it should be remembered that the power to make compensation orders has been available for decades but has been rarely used in consumer protection cases. The OFT Annual Report for 2011-12 identified that the 1860 prosecutions under consumer protection legislation resulted in less than $£ 100,000$ of compensation in total. While this relates to a period before the 2012 Act (when there was merely a discretion to consider compensation orders) it is not clear that the legislation will make a significant difference. One reason is that in consumer protection cases, the criminal courts will seldom have details of all victims at the time of sentencing. As a result, the compensation order may not be an appropriate method of providing redress. Another is that an important aim of ECMs is to take cases away from the criminal courts, so in most cases where redress would be appropriate there will be no prosecution for a compensation order to follow. ${ }^{70}$

A second development is that the Consumer Protection (Amendment) Regulations 2014 give consumers private law rights where certain provisions of the CPRs are

\footnotetext{
${ }^{69}$ Macrory box E2.

${ }^{70}$ Given the compliance stance of enforcers prosecution is not the norm now.
} 
breached. Where a consumer enters into a contract or makes a payment, the trader engages in a prohibited practice (meaning an aggressive or misleading action) and that practice is a significant factor in the consumer's decision to enter the contract or make the payment, the consumer will be entitled to redress. ${ }^{71}$ If the trader does not voluntarily pay compensation, the consumer will need to pursue the matter. This may be made easier with the implementation of the Directive on Consumer ADR by the Alternative Dispute Resolution Regulations 2015. The Directive aims to give EU consumers the opportunity to resolve disputes without going to court, regardless of product, the service type or the place of purchase. Although there is no obligation on most traders to agree to use ADR it will in practice give many consumers an additional avenue for redress. One interesting argument that might be made is that the existence of alternative routes to redress (such as ADR) makes redress schemes disproportionate. However, compensation orders, the private right to redress and ADR are all best-suited to cases where there is one victim, or a small number of easily identifiable victims. In cases where loss is more widespread, ECMs are likely to be particularly appropriate.

\section{Limitations and innovations}

There remains a lack of detail about how redress schemes will operate, but some aspects (and limitations) are clear. BIS has stated that the remedies would be based around "mechanistic schemes to deliver particular outcomes rather than the outcomes themselves" and that "performance would therefore be based on the technical requirements of the individual schemes." ${ }^{12}$ This means that consumers may not get $100 \%$ of their money back through a scheme. For example, there will be cases when a large number of consumers have suffered different levels of loss. It may be judged in such cases that it would not be just and reasonable to impose a scheme, or that it would only be just and reasonable to do so if a trader can make consumers an offer based on the average of the loss. ${ }^{73}$ This would merely be an offer. There is no obligation on consumers to accept that offer and they can always pursue other means to obtain redress. It will, however, be possible for the trader to require that if a consumer accepts redress under the Scheme he or she waives the right to take additional action to recover the money. ${ }^{74}$ They cannot, however, require the consumer to waive any right in relation to other conduct of the business. Where consumers may not receive $100 \%$ of their loss this would have to be made clear to them. There may be other ways in which schemes are potentially less attractive than alternatives. For example, a redress scheme might set

\footnotetext{
${ }^{71}$ Regulation 27A.

72 BIS Consumer Rights Bill: Proposals on Enhanced Enforcement Remedies Impact Assessment: Final (“Impact Assessment") (June 2013) para 44

73 See 2015 Guidance para 59.

742015 Guidance para 58.
} 
its own remoteness rules to govern what is within its scope. It is not clear to what extent traders will be required to draw attention to all such matters, and it is vital that consumers are aware of their options. This does create the danger that consumers will be overwhelmed with options. One of the aims of the review of consumer law was simplification, but the redress landscape is arguably as complex as, if not more complex than, ever.

One innovative aspect of the Redress Category is that enforcers may use it to pursue measures that are in the collective interests of consumers. An example of how this might operate is provided in the Guidance. ${ }^{75}$ In this example, a petrol station with a record of compliance was discovered to have faults with 3 of its 12 pumps, resulting in their dispensing a quarter of a litre less fuel than is shown on the pump. Working with the enforcer, the owner discovered that the faulty pumps had been used 5000 times with each customer being overcharged $£ 3$ on average. It was not possible to identify the affected customers, at which point the owner became uncooperative. The enforcer judged that it would not be just, reasonable and proportionate to require the business to try to compensate the individual customers in these circumstances. The low amount of loss per customer and the difficulty of identifying the customers in question meant that a redress measure to compensate them would not be appropriate. In cases such as this, ECMs allow action to be taken which removes the profit from the activity, but does not compensate the affected consumers. The Guidance suggests that in this case, the enforcer could bring a civil action to obtain an order for the business to pay $£ 15,000$ to a local consumer charity. In some cases an ECM might include a combination of compensation to consumers and a payment in the collective interests of consumers. For example, if the business were able to identify a proportion of individual consumers who had been overcharged, such as those who had paid by credit card, it would be possible to require the business to compensate those and to pay the balance (up to the amount the business had benefited from the error) to charity. ${ }^{76}$

Some difficult questions are left unanswered. For instance, in the example above the trader paid $£ 15,000$ to a charity because it was deemed that consumers could not be traced. In other cases, those consumers who could be traced were compensated, and a payment made to a charity to reflect the difference between the compensation and the benefit gained. In both cases, the trader paid an amount to reflect the gain. But what happens if the other consumers subsequently come forward to demand compensation? It is presumed that they will be compensated through other means and it is foreseeable that this will happen. As explained above, redress measures cannot be used where the cost of the measures is unlikely to be more than the sum of the losses suffered by

\footnotetext{
${ }^{75} 2015$ Guidance Case Study 6.

${ }^{76}$ Ibid.
} 
consumers. In such a case the cost of the measures is not (it is $15 \mathrm{k}$ and the consumers have lost $15 \mathrm{k}$ ) but the total cost to the business will be more if it also has to compensate individuals outside those measures. It might be possible for businesses to argue that the uncertainty about whether consumers will pursue action for redress makes a payment to charity which reflects the full amount lost disproportionate. It is submitted that such an argument should fail. It is important that the business in question does not benefit from its wrongdoing (even where that wrongdoing lacks any significant culpability) and that consumers should not lose their right to compensation. A difference can be drawn between the amount of the redress measures (in this example 15k) and the amount of the redress ( $15 \mathrm{k}$ plus redress paid outside the measures).

It is important the traders take all reasonable steps to contact affected individuals, for example by advertising in national, regional or specialist press and by making use of social media. It will be up to enforcers and the courts to ensure that they do this. However, traders may be under incentives not to take such steps. For instance, they may regard it as simpler and potentially more beneficial to pay money to charity and try to gain some positive publicity for doing so. There is evidence that under RESA, traders will frequently make charitable donations (such as to environmental groups) as part of an enforcement undertaking. ${ }^{77}$ It should be noted that where areas such as environmental law are concerned, paying money to a charity may be more appropriate than paying to victims, because of the difficulty of identifying (let along quantifying loss to) them. Nevertheless, there are many concerns with using charitable donations as an alternative to punishment. It is not possible to do them justice here, but particular concerns include who decides on the recipient and on what basis, what accountability (if any) there is over donations. ${ }^{78}$ Furthermore, there must be concern that a donation is interpreted by the public as an act of generosity and goodwill rather than as a sanction for wrongdoing. Regulatory Justice identified one of the weaknesses of regulatory offences as being the failure of prosecution to reflect stigma accurately. It is vital that traders do not use these measures to gain underserved positive publicity. ${ }^{79}$

\section{ECMs: The Compliance Category}

Section $219 A(3)$ states that the measures in the compliance category are:

"measures intended to prevent or reduce the risk of the occurrence or repetition of the conduct to which the enforcement order or undertaking relates including

\footnotetext{
${ }^{77}$ See O.W. Pederson "Environmental Enforcement Undertakings and Possible Implications: Responsive, Smarter or Rent Seeking?” (2013) 76(2) M.L.R 319.

${ }^{78}$ Ibid, 333-341.

${ }^{79}$ In a slightly different context, see the case study on Kepone and Allied Chemical in B. Fisse and J. Braithwaite The Impact of Publicity on Corporate Offenders (Albany 1983) chap 6.
} 
measures with that purpose which may have the effect of improving compliance with consumer law more generally."

The focus here is not on looking at how redress can be provided for past breaches, but on how future breaches might best be avoided. Regulatory Justice pointed to "compliance deficit" being one of the limitations of prosecution, with courts and enforcers limited in their ability (a) to require firms to act in specific ways to bring themselves back into compliance; and (b) to ensure that breaches are less likely to happen in future. Whereas Macrory saw these functions being achieved through compliance notices, the CRA envisages their being delivered through the compliance category of ECMs. As with the redress category, there is an emphasis on flexibility and this explains why there is no list of actions in the Legislation. However, the Guidance does identify some possible measures which appear to fall within this category, namely: signing up to a Primary Authority Scheme; appointing a compliance officer; providing better staff training and guidance; undertaking internal spot checks (and keeping records of these); collecting and acting on consumer feedback; introducing a robust complaints handling scheme; and signing up to a certified ADR Scheme and committing to be bound by its decisions. ${ }^{80}$

The Guidance gives an illustration of how this power might operate. In this example, a consumer paid an online retailer an additional fee for next day delivery but found that the goods were delivered late. Enforcers investigated and discovered that this was the result of short-term staff shortages and poor staff training. Some steps were taken voluntarily by the firm: consumers were refunded their additional fee and temporary staff were sought. However, the firm refused to take steps to improve the staff training which enforcers believed to be necessary to avoid repetition of the delays. The enforcer sought an enforcement order to change and improve staff training and to designate a member of staff to act as a customer complaints manager. The Court regarded the proposed measures are just, reasonable and proportionate and that they would ensure there is no repeat of the breach. ${ }^{81}$

There are a number of difficulties with this example. First, it is rare that such facts would arise. A trader that is generally compliant and responsible would be unlikely to refuse to improve staff training or agree that a member of existing staff be given the responsibility of acting as a customer complaints manager. A business might object to being made to employ an entirely new member of staff to take on such a role, but it is doubtful that this would be demanded of a small firm as it is unlikely that that would be just reasonable and proportionate. Second, the example concerns legislation that has been breached "inadvertently". It is easy to see compliance measures as a more

\footnotetext{
${ }^{80} 2015$ Guidance para 46.

${ }^{81} 2015$ Guidance Case Study 7.
} 
appropriate response than prosecution in such cases. It is also clear that being able to add ECMs to undertakings makes them more useful than would previously have been the case. However, it will still be easier for enforcers to deal with such situations through informal means such as education and advice and, where breaches are inadvertent, they are likely to be resolved in this way. The compliance strategies that provide the basis of so much enforcement activity will remain the norm. Some cases will lead to undertakings, as the enforcer may want to firm up the traders good intentions. But relatively few are likely to lead to enforcement orders being sought, particularly given the procedural obstacles to such orders discussed earlier.

The compliance category appears to address a number of concerns with the previous law. Its flexibility is perhaps its greatest strength, allowing it to be shaped to be responsive to the circumstances of the breach. One criticism of previous law is that it did not focus sufficiently on changing behaviour. The compliance category has changing behaviour at its core, not through deterrence, but through specifying what is necessary for future compliance This should reduce what Regulatory Justice referred to as compliance deficit. But some concerns remain. One is that whether the process is resource-intensive depends to a large extent how the trader engages with it. As noted above, if enforcers are expected to come up with solutions, there is a danger that traders may act in ways that make it difficult for resolution to be achieved. While this is less likely in cases where legislation is breached inadvertently and the trader generally displays a willingness to comply, some traders will not be inclined to be so co-operative. Enforcers may not be able to commit the resources they would like to pursue matters further and thus may be under incentives to agree to measures that are less than optimal. Where measures are proposed by the enforcer, there is likely to be debate over the reasonableness and proportionality of the proposals. It is up to the enforcer to quantify matters in order to be able to establish proportionality, but it has been noted that this will be very difficult in practice. An enforcer may well believe that a trader's protests are disingenuous, but will find it difficult to prove that. So long as it is up to the enforcer to demonstrate that proposals are not unjust unfair or disproportionate, this problem will remain.

\section{ECMs: The Choice Category}

Section 219A(4) states that measures in the choice category are: "measures intended to enable consumers to choose more effectively between persons supplying or seeking to supply goods or services." The rationale for the choice category (labelled curiously as "Consumer Information Measures" in the Guidance) was said to be the Government's enthusiasm for seeing more confident consumers who are empowered to exercise 
greater consumer choice and thus improve the functioning of the relevant market. ${ }^{82}$ In the Guidance, the example is of a business that described itself as closing down and offering price reduction of $25 \%$ "this weekend only". In fact, there was no price reduction and the business was not closing down. ${ }^{83}$ In the example, a court order was obtained requiring the business to display notices in store, on the website, on social media and in the local press notifying consumers of their actions.

The principal focus of the choice category appears to be upon communicating negative information about a business to consumers in order to assist them in exerting market discipline. This is a particularly interesting power and needs to be viewed through the lens of regulated adverse publicity (hereafter adverse publicity). ${ }^{84}$ It has been argued that adverse publicity can play two roles in consumer protection law and policy: it can operate as a sanction in its own right; and it can play a role in helping consumers to exert market discipline by making informed choices about suppliers. ${ }^{85}$ In relation to the first of these, enforcers use negative publicity as a sanction under a number of regulatory regimes, with the publicity forming either the whole, or a part of the sting of the penalty. For example, the Financial Conduct Authority (FCA) issues public censure under the Financial Services and Markets Act 2000 as a formal disciplinary tool, and may also use adverse publicity alongside another sanction (for example when it issues a press release following the imposition of a financial penalty). The basis for using adverse publicity as a sanction could be viewed as just deserts, but is more likely to be explained on the basis of deterrence. Many traders will fear the impact of adverse publicity and where they are motivated solely by profit the threat of such publicity may deter potential wrongdoing. Indeed, the Hampton Review suggested that reputational sanctions worked particularly well in the area of consumer protection. ${ }^{86}$

It is the second role of adverse publicity, that of helping consumers to make informed choices, which more obviously forms the basis of choice measures. In classical economic theory, consumers make choices in accordance with their preferences in an environment where they have a wide choice of suppliers and products and perfect (or optimal) information upon which to make that choice. ${ }^{87}$ It is unrealistic to expect these factors to be present in all (or indeed many) markets, but adverse publicity through choice measures may help to fill some information gaps. Choice measures may help to ensure that consumers are informed about matters of importance to them. To make informed choices, consumers are said to need information about price, quality and terms

\footnotetext{
${ }^{82}$ BIS Civil Enforcement Remedies para 4.

832015 Guidance Case Study 8. Such practices are not uncommon.

${ }^{84}$ See P. Cartwright "Publicity Punishment and Protection: the role(s) of adverse publicity in consumer policy"

2012 32(2) Legal Studies 179.

${ }^{85}$ Ibid.

${ }^{86}$ Hampton para 3.64.

${ }^{87}$ London Economics Consumer Detriment under Conditions of Imperfect Information (London 1997).
} 
of trade and an unregulated market will not always provide this. ${ }^{88}$ Choice measures can be used to disclose information about the quality (broadly understood) of the provider, for example by informing consumers about wrongdoing. The consumer for whom the integrity or competence of a supplier is important can thus be informed about that.

When making its original case for reform, the Government argued that there was a gap in consumer information "about where companies have broken the law or failed to offer a good service. ${ }^{\prime 89}$ Choice measures will only be used where there is a breach of the law. They will not, therefore, be appropriate in all cases of, say, poor service. This might be viewed as a regrettable limitation. Brooker, for example, argues, that "as a matter of principle, consumers have a right to know when the behaviour of a business casts serious doubts on its integrity or competence. ${ }^{\prime 90}$ Choice remedies might appear only to go so far towards addressing this because of their being rooted in a breach of the law. However, it should be remembered that the consumer laws that form the basis of ECMs are extremely broad, even where, as in this article, the focus is on the criminal law. The CPUTRs, for example, prohibit a wide range of wrongdoing. As well as banning misleading actions and omissions, aggressive commercial practices and a range of specific matters, they state that a commercial practice is unfair if it "contravenes the requirements of professional diligence and it materially distorts or is likely to materially distort the economic behaviour of the average consumer with regard to the product." According to regulation 2(1), "professional diligence" means:

"the standard of special skill and care which a trader may reasonably be expected to exercise towards consumers which is commensurate with either

(a) honest market practice in the trader's field of activity; or

(b) the general principle of good faith in the trader's field of activity."

Conduct that reveals a lack of integrity will be well-suited to choice measures, particularly where the basis of the choice remedy is the need to name and shame the trader. Whether evidence of incompetence is fitting for a choice remedy is less clear. The requirement of professional diligence is probably broad enough to cover this, and as has been noted above, an argument for informing consumers about competence as well as integrity. ${ }^{91}$ To the extent that they concern competence, choice remedies must be used with some care. For example, where traders are flagged on a naming and shaming

\footnotetext{
88 Ibid.

${ }^{89}$ Civil Enforcement Remedies para 3.22

${ }^{90}$ S. Brooker Regulation and Reputation (London 2006) p 7

${ }^{91}$ Unusually the professional diligence provision requires proof of mens rea, although what precisely that entails remains unclear. See P. Cartwright "Unfair Commercial Practices and the Future of the Criminal Law" [2010] (7) JBL, 619.
} 
website, care needs to be taken to identify how, precisely, they have fallen short. For them to be "shamed" there has to be some wrongdoing deserving of such shame, and it is easy for consumers to misinterpret adverse publicity. The distinction between naming and shaming websites, and customer review/feedback sites is by no means a clear one. Reference was made above to the danger that prosecution will sometimes be a disproportionate response to breach, and one reason for this is that it might be taken to imply stigma when such stigma was not deserved. Traders may, of course, challenge orders which contain ECMs on the basis of their being disproportionate, but one problem with adverse publicity is that its impact is difficult to quantify, particularly in advance.

It is worth digging a little more deeply into the issue of proportionality here. As noted above, ECMs must be just, reasonable and proportionate. Where an enforcer seeks an undertaking, it is likely that there will be discussion about the justice, reasonableness and proportionality of what is being proposed during the process of consultation. Where an enforcement order is sought, the trader may challenge this. This occurred in Office of Fair Trading $\vee$ Purely Creative and Others where the defendants argued that they had not breached the relevant legislation (in this case the CPUTRs) and, in the alternative, that the order sought went far beyond that required to secure compliance and was too generalised for the defendants to know what they were to be prohibited from doing. ${ }^{92}$ Where an order is sought, it will mean either that it has not been possible to obtain assurances or that assurances obtained have been breached. The court will be able to take a range of factors into account when deciding whether an order might be unjust, unreasonable or disproportionate. The decided cases on enforcement orders are not particularly helpful as they do not concern ECMs. The lack of detail in legislation as to what ECMs may require is deliberate so as to allow a maximum degree of flexibility. As has been shown, the Guidance provides some assistance, but significant doubt remains about how willing the courts will be to make orders which place what might be viewed as onerous demands on traders. One difficulty is that the Guidance provides relatively obvious examples of conduct that would justify orders containing ECMs: a garage owner who becomes uncooperative after over-changing customers; an online retailer which refuses to improve staff training after breaching a promise of next day delivery; and a business that describes itself as offering a price reduction and closing down when neither is true. The respective requirements in the orders appear eminently reasonable: payment of the amount wrongly obtained to a local charity; improving staff training and designating a member of staff as consumer complaints manager; and requiring the business to display notices in store, on the website, on social media and in the local press notifying consumers of what they have done wrong. There will be far more difficult cases in practice where the court will have to consider the impact on the trader and the

\footnotetext{
${ }^{92}$ [2011] EWHC $106(\mathrm{Ch})$ para 5.
} 
benefit to consumers in far more detail to ascertain whether the order might be unjust, unreasonable or disproportionate. Particular difficulty is likely to arise where the enforcer seeks an order to use ECMs in combination. It was noted above that while redress measures will typically take precedence when using ECMs in combination might be disproportionate, it will sometimes be possible to use all three measures in combination. It is important that the courts show a willingness to accept such measures where significant benefits would be obtained. It should be remembered that the different categories of ECM have discrete and important objectives. Redress measures are largely concerned with compensation; compliance measures with reducing the probability of further contraventions and choice measures with improving the ability of consumer to make informed choices and exert market discipline. It is perhaps where choice measures form part of the order that disproportionality is most likely to arise. This is because it is the measure whose impact is most difficult to predict. While there is evidence that similar powers can work well as a deterrent, and as such as a way of raising standards and improving compliance, this is partly because of the danger that they might operate in a disproportionate manner. ${ }^{93}$ Literature on adverse publicity reveals significant concern that the impact of negative information can be disproportionate. ${ }^{94}$ It may be that where choice measures form part of an enforcement order that traders will have the best chance of challenge on the bases of justice, reasonableness and proportionality.

A further point is that if there is significant wrongdoing we might expect more explicit punishment. In particular, where conduct is deserving of shame, we might expect prosecution to follow so as to reflect that. ${ }^{95}$ It has been noted that adverse publicity can operate as a form of punishment, but there is a reluctance to view ECMs in this way. It is to the relationship between ECMs, prosecution and punishment that we now turn.

\section{ECMS, PROSECUTION AND THE RETREAT FROM PUNISHMENT}

When ECMs were first proposed there was considerable doubt about whether they could be used alongside prosecution. The Government was eager to move cases from criminal to civil courts and, where undertakings were secured by enforcers, out of the courts altogether. One sentence in the Consultation was a particular cause for concern: "[t]he option of achieving remedies of this type may only be appropriate [my emphasis] where

\footnotetext{
${ }^{93}$ See K. Yeung Is the Use of Informal Adverse Publicity a Legitimate Regulatory Compliance Technique? (Melbourne 2002) 40.

${ }^{94}$ J.C. Coffee Jr "No soul to damn no body to kick: an unscandalized inquiry into the problem of corporate punishment” (1981) 79 Mich L Rev 386; Yeung pp 40-41.

${ }_{95}$ Not that shame operates only in a retributive sense. See J. Braithwaite Crime, Shame and Reintegration (Cambridge 1989)
} 
there is no wider public interest in criminal prosecution." 96 This implied that prosecution and the securing of ECMs were incompatible. ${ }^{97}$ This was extremely concerning.

As has been explained above, ECMs play an important role in addressing many of the shortcomings associated with the enforcement of consumer protection law. Despite their limitations, they will make it easier for courts and enforcers to secure redress, achieve compliance and facilitate choice. But they do not sanction the trader, in the sense of imposing a punishment. There will be many cases where the imposition of punishment is not only desirable but essential because of the wrongdoing involved. Were prosecution to be unavailable alongside ECMs, how should enforcers approach a trader who engaged in conduct that undoubtedly warranted a criminal penalty, but which also led to significant loss to consumers? Denying access to ECMs on the basis that a prosecution is necessary would be perverse. Enforcers have always been able to use Part 8 alongside criminal prosecution, but the Government appeared not to appreciate this. In its response to consultations, the Government stated that "as an alternative [my emphasis] to criminal prosecution" consumer law enforcers can seek an Enforcement Order."

The Guidance now makes clear that while in most cases where the measures are appropriate they will be an alternative to criminal prosecution, "there may be cases where the offences are serious enough to warrant them being used in conjunction with criminal prosecution". ${ }^{99}$ A case study in the Guidance gives an example of how prosecution might be used alongside ECMs. It concerns a business selling mobility aids through a combination of cold calling and high pressure doorstep selling. In addition the products supplied were often not fit for purpose and priced at an amount higher than that originally quoted. ${ }^{100}$ The company and its directors were prosecuted and a conviction was achieved. The enforcer then obtained an enforcement order under the redress category. The 20 consumers who wanted to return their mobility aid and obtain a refund were able to do so, while the five consumers who wanted to keep their aid received the difference between the price quoted and the price paid.

The decision to allow prosecution to be taken alongside the ECMs is undoubtedly the correct one, and the example given is one where prosecution and ECMs should be able to work together. But the reluctance of the Government for the two to be combined remains a deep cause for concern. The desire to move cases from the criminal courts is understandable, and there is little doubt that there will be breaches of consumer

\footnotetext{
${ }^{96}$ Civil Enforcement Remedies para 1.8.

${ }^{97}$ This was indeed the view of BIS at the time (discussion on file with the author).

${ }^{98}$ Civil Enforcement Remedies para 5.

992015 Guidance p 5.

1002015 Guidance case study 2.
} 
protection law that do not warrant prosecution. ${ }^{101}$ But it far from clear that the majority of the cases that currently lead to prosecution should be dealt with outside the criminal process. Enforcers exercise considerable discretion before deciding to prosecute, taking into account a range of factors such as the culpability and attitude of the trader and the degree of harm caused. ${ }^{102}$ As a consequence, many of the prosecutions for consumer protection offences that currently take place are those where the enforcer believes significant culpability to be present. This will not always be apparent to those who are not directly involved with the case. Moreover, because the offences are generally of strict liability, mens rea will not be central to guilt. ${ }^{103}$

There is a significant danger that in the move towards ECMs, we lose the benefits that prosecution brings. Compelling arguments can be made to defend the use of prosecution in the context of consumer protection law, particularly if we think about the rationales for the imposition of punishment. Two aims are particularly relevant: retribution (particularly in the form of just deserts) and changing behaviour (particularly through deterrence).

ECMs are not punishments and they can be used where the language of punishment is not appropriate. However, where consumer protection law is breached, punishment frequently is appropriate. A primary aim of punishment is retribution, usually expressed as "just deserts". ${ }^{104}$ A punishment is imposed to reflect the wrongdoing in which the trader has engaged. Indeed, Regulatory Justice argued that an aim of a penalty is to be responsive and that this involves considering what is appropriate for the particular offender and regulatory issue. It was recognised that this can include punishment and the public stigma that should be associated with a criminal conviction. If cases are diverted from the criminal courts to negotiations between enforcer and trader and (occasionally) from criminal to civil courts there is a danger that this is lost. Appropriate labelling is particularly important in the most serious cases, i.e. where there is significant harm and/or significant culpability. It was suggested above that the Government's calls for the criminal law to be reserved for "out and out rogues" is mistaken from the perspective of just deserts. There are other cases where the label of criminality is appropriately imposed in the absence of traditional, subjective mens rea, in the form of intention or dishonesty. An example might be where the harm caused is substantial and the trader clearly should have done more to take care. Traders who breach norms carelessly but unintentionally have been characterised by Kagan and

\footnotetext{
${ }^{101}$ Trading Standards estimated that 476 cases which were prosecuted in 2011-12 might have been suitable for civil action had better remedies been in place. See BIS Impact Assessment para 16.

${ }^{102}$ P. Cartwright Consumer Protection and the Criminal Law 222-230.

${ }^{103}$ It will be relevant in some cases, such as where directors are prosecuted for offences committed by their companies with their consent connivance and neglect, and potentially in cases where a defence such as due diligence is pleaded.

${ }^{104}$ A. Von Hirsch Doing Justice (New York 1976).
} 
Scholz as the "organisationally incompetent". ${ }^{105}$ Not all incompetence justifies a criminal label, but some does. That the criminal law has a role in tackling traders who could be expected to do more is recognized through offences that impose objective forms of mens rea (such as gross negligence manslaughter and corporate killing) and also through strict liability offences which are subject to due diligence defences. The offences contained in the CPRs are examples of this; the criminal law states, in effect, that D should have done more and is being punished for failure to act in an appropriate manner. This can be justified in part on the basis of just deserts. Many cases of incompetence will be diverted from the criminal courts (as in practice they have been for decades). But if just deserts and appropriate labelling are to be achieved, those involving the most serious neglect should remain.

A second aim of imposing punishment/penalties is to change behaviour. The extent to which ECMs achieve this has been discussed above, particularly in the context of compliance measures. Traditional theories of punishment can be divided between those that are consequentialist and those that are non-consequentialist. Retribution is a non-consequentialist theory; the punishment is imposed to reflect the defendant's wrongdoing. However, of more obvious relevance to consumer protection are consequentialist theories. ${ }^{106}$ These justify punishment on the basis of the need to change the defendant (or at least, the defendant's conduct). Where regulatory offences are concerned, changing behaviour is perhaps the principal aim of prosecution (or, indeed, other forms of penalty). This might be conceived in different ways. For example, we might punish in order to deter the trader from engaging in similar conduct in future (individual deterrence) or in order to deter others from committing similar wrongdoing (general deterrence). It might be argued in some cases that punishment has a role in rehabilitation, although this is likely to be rare. ${ }^{107}$

There are significant concerns with the notion of deterrence in the narrow sense of deterring someone from deliberately breaking the law. Regulatory Justice focused of course on the shortcomings of prosecution for regulatory offences and there is no doubt that prosecution (and in particular, the consequences of being prosecuted) were inadequate. The importance of enforcers providing "credible deterrence" has come particularly to the fore in some areas, such as financial regulation. ${ }^{108}$ The need to deter substantial wrongdoers is also recognized by the Government's reference to "out and out rogues". It is also worth noting, that since subsections (1), (2) and (4) of s. 85 of the

\footnotetext{
${ }^{105}$ R. Kagan and J. Scholz "The "Criminology of the Corporation" and Regulatory Enforcement Strategies" in K. Hawkins and J. Thomas (eds) Enforcing Regulation (Dordrecht1984).

${ }^{106}$ C. Wells Corporations and Criminal Responsibility $2^{\text {nd }}$ ed (Oxford 2001) chap 2.

${ }^{107}$ P Cartwright Consumer Protection and the Criminal Law 78-79.

108 See T. McDermott "Enforcement and Credible Deterrence in the FCA" available at: http://www.fca.org.uk/news/speeches/enforcement-and-credible-deterrence-in-the-fca (accessed 10-8-15).
} 
Legal Aid, Sentencing and Punishment of Offenders Act 2012 were brought into force (on $12^{\text {th }}$ March 2015) magistrates' courts have not been restricted to specified upper limits when deciding the level fine to impose upon defendants. This will apply to some pieces of consumer protection legislation. It means that at least in some cases, it is possible for the courts to impose penalties that are more likely both to deter, and to reflect the degree of wrongdoing involved.

As has been recognized, some traders are amoral calculators, incentivised to comply only by the credible threat of a compelling sanction. ${ }^{109}$ There seems to be broad agreement that deterrence, achieved through the criminal law, has a role in dealing with such traders. But a number of caveats should be added. First, it is far from clear that enforcers will be inclined to prosecute even where there is evidence of mens rea. The push towards moving cases from criminal to civil courts is likely to mean that some cases which involve high levels of culpability are diverted away from the criminal process. Second, there is a compelling argument that threatening prosecution focuses the minds of traders and incentivises them to take greater care, and to devote more resources to checking, monitoring, supervising, and training. This has been seen as a rationale for regulatory offences. In the Trade Descriptions case of Wings $\vee$ Ellis, Lord Scarman famously said that the point of prosecution was not the enforcement of the law so much as the maintenance of trading standards. ${ }^{110}$ It has been recognized that when the criminal law is used against businesses, its purpose includes the encouraging of good practice. ${ }^{111}$ Consumer protection offences are examples of regulatory offences which incentivise care by being subject to due diligence defences. A trader who has done all that he or she reasonable could to avoid the commission of the offence is not guilty. Some of this risks being lost in the move away from the prosecution. It is hoped, of course, that the wish to avoid ECMs will also encourage good practice. It should also be remembered that informal enforcement takes place against the background of the threat of more formal action. It may be that knowledge on the part of traders that enforcers can prosecute, and courts can impose ECMs will focus the minds of traders on their obligations. But the obstacles placed in the way of formal action make this less of threat than it might be.

\section{CONCLUSIONS}

There is little doubt that the ability of the courts and of enforcers to secure positive outcomes for consumers is strengthened by the creation of ECMs. The weaknesses of relying on the prosecution of traders and the seeking of undertakings and enforcement orders to deliver the aims of consumer protection law are well-established; at least some

\footnotetext{
${ }^{109}$ Kagan and Scholz "the Criminology of the Corporation".

${ }^{110}$ [1985] A.C. 272, at 293.

${ }^{111}$ C. Wells Corporations and Criminal Responsibility 31.
} 
of these weaknesses are addressed directly by the ability of enforcers to pursue ECMs. Macrory identified two of the weaknesses of regulatory offences as their inadequate focus on the victim and their tendency to lead to a compliance deficit. ${ }^{112}$ Redress measures will assist enforcers in obtaining redress (and in particular compensation) for consumers where other tools impose barriers, thus allowing greater focus on the interests of the victim. Compliance measures should address compliance deficit by making it easier for enforcers to procure agreements from, and the courts to impose requirements on, traders, thus reducing the probability of future contravention. Choice measures will not only allow for the dissemination of information that is likely to improve consumer decision-making but will also provide a further incentive for traders both to choose to comply in the first place, and to choose to take care to avoid careless breaches that might lead to negative publicity. Although ECMs are not generally conceived as sanctions or penalties, they may operate as such in some cases. To the extent that they do, they may sometimes operate more successfully as a deterrent, and better reflect the stigma that should attach to a particular contravention, than would prosecution. The existence of ECMs means that enforcers will sometimes be able to negotiate better outcomes for consumers who have suffered detriment, while putting in place measures to reduce the chances of conduct being repeated.

Despite these advances, concerns remain. The procedural obstacles that enforcers face will frequently make it difficult for them to achieve optimal outcomes. It is disappointing that rather than overcome these obstacles, the changes may have in some respects have increased them. It is extremely important that prosecution can be used alongside ECMs. Had they been alternatives, as was originally mooted, enforcers would have found themselves in the undesirable position of choosing between the seeking of positive outcomes for consumers, and the imposition of an appropriate penalty upon a wrongdoer. Typically, this would be a choice between restoration or retribution when both were demanded. Despite what was said above about the potential for an ECM to sometimes operate in a manner similar to a punishment, they are no substitute for prosecution where the seriousness of a transgression justifies that response. However, it is important not only that enforcers can pursue prosecution where that is the most fitting response, but that they do so. The Government's reluctance to see these actions being taken in combination may still translate into cases which deserve prosecution being diverted from the criminal courts. This is regrettable in terms of appropriate labelling, but also from an instrumental perspective, as it may reduce the ability of the law to incentivise compliance. In this regard the changes introduced by the Consumer Rights Act 2015 can be seen as both a step forward and a step backwards.

${ }^{112}$ Macrory paras 1.21 and 2.27. 
